\title{
Serum Levels of Neutrophil Gelatinase-Associated Lipocalin (NGAL) as Predictor of Acute Kidney Injury in Sickle Cell Subjects
}

\section{Adedeji David Atere ${ }^{1,2 *}$, Olumide Faith Ajani ${ }^{3}$, David Bolaji Akinbo ${ }^{4}$, Omobolaji Adewumi Adeosun ${ }^{1}$ and Odiaka Mark Anombem ${ }^{5}$}

${ }^{1}$ Department of Medical Laboratory Science, Achievers University, Owo, Ondo State, Nigeria

${ }^{2}$ Department of Medical Laboratory Science, University of Benin, Benin City, Edo State, Nigeria

${ }^{3}$ Axios Foundation, Nigeria

${ }^{4}$ Department of Medical Laboratory Science, Afe Babalola University, Ado Ekiti, Ekiti State, Nigeria

${ }^{5}$ St Luke's Hospital, Asaba, Delta State, Nigeria

Received date: Dec 10, 2018; Accepted date: Dec 20, 2018; Published date: Dec 24, 2018

${ }^{*}$ Corresponding author: Adedeji David Atere, Department of Medical Laboratory Science, Achievers University, Owo, Nigeria, Tel: +2348039501172; E-mail: ateread@gmail.com

Copyright: (C) 2018 Atere AD, et al. This is an open-access article distributed under the terms of the Creative Commons Attribution License, which permits unrestricted use, distribution, and reproduction in any medium, provided the original author and source are credited.

Citation: Atere AD, Ajani OF, Akinbo DB, Adeosun OA, Anombem OM (2018) Serum Levels of Neutrophil Gelatinase-Associated Lipocalin (NGAL) as Predictor of Acute Kidney Injury in Sickle Cell Subjects. J Biomedical Sci Vol.7 No.4:17.

\section{Abstract}

Background: Neutrophil Gelatinase-associated Lipocalin (NGAL) has generated great interest as a novel biomarker for the timely detection of Acute Kidney Injury (AKI). This study, therefore, investigated NGAL as a predictive marker for acute kidney injury among sickle cell subjects.

Materials and methods: A total of fifty (50) sickle cell subjects aged $18-60$ years and attending the sickle cell clinic of Federal Medical Centre, Owo were randomly recruited along with twenty-five (25) apparently healthy age and sexmatched non-sickle cell subjects attending the family medicine outpatient clinic of the hospital as control for the study. Plasma levels of NGAL were assessed using an Enzyme-Linked Immunosorbent Assay (ELISA) kit, while urea and creatinine were determined by standard spectrophotometric method. The results were statistically analyzed for significance at $p<0.05$ using one-way analysis of variance (ANOVA).

Results: NGAL and urea plasma levels were significantly $(p<0.05)$ increased in the steady and vaso-occlusive (VOC) sickle cell subjects, glomerular filtration rate showed significant $(p<0.05)$ reduction in both steady and VOC groups compared to the normal healthy control. The levels of urea and creatinine were increased significantly $(p<0.05)$ in the VOC sickle cell group compared with the steady sickle cell group, whereas circulating levels of NGAL showed a significant $(p<0.05)$ reduction in VOC sickle cell group compared with the steady sickle cell group. NGAL revealed an excellent higher area under the receiver operating curve than urea and creatinine.

Conclusion: NGAL was shown to be a sensitive tool, an early biomarker for acute kidney injury in sickle cell subjects and clinically significant for its wide availability, easy accessibility, and sensitivity in aiding early detection with a dynamic wide range for routine assessment in the management of SCD.

Keywords: Sickle cell disease; Neutrophil gelatinaseassociated lipocalin; Glomerular filtration rate; Acute kidney injury

\section{Introduction}

Acute Kidney Injury (AKI) which was previously known as Acute Renal Failure (ARF) is a sudden loss of kidney function that develops within a week and it is caused by numerous factors [1]. Generally, it occurs due to damage to the kidney tissue resulting from a decrease in blood flow to the kidney (kidney ischemia) with causal factors varying from low blood pressure, exposure to substances that may initiate the inflammatory process in the kidney, to obstruction of the urinary flow tract. AKI is diagnosed on the basis of characteristic laboratory findings, such as elevated blood urea nitrogen and creatinine, or due to anuria while people who have experienced AKI may have an increased risk of chronic kidney disease in the future. The management of AKI includes treatment of the underlying cause and supportive care, such as renal replacement therapy [2].

Sickle cell disease is a chronic inflammatory state characterized by a unique morphological abnormality of red blood cells which results in vaso-occlusion with ischaemic tissue injury, chronic hemolytic state and co-morbid conditions [3]. However, the renal manifestations of Sickle Cell Disease (SCD) range from various functional abnormalities to gross anatomical alterations of the kidneys. The inner medulla's relatively hypoxic, hypertonic, and acidotic environment is known to predispose Red Blood Cells (RBCs) to sickle, which significantly decreases renal medullary blood flow through vaso-occlusion $[4,5]$. At the 
same time, haematuria; which is commonly seen in patients with sickle cell nephropathy, increases venous pressure subsequently aggravating ischemia of the renal medulla thereby predisposing the patients to further RBC sickling [6]. Chronic kidney failure due to sickle cell nephropathy presents with hypertension, loss of protein and red blood cells through the urine, worsened anemia and carries a poor prognosis upon progression to end-stage renal failure [7].

The clinical presentations of acute kidney injury often differ depending on the cause and may include excretion of too little urine, pedal edema, puffy eyes, fatigue, dyspnea, confusion, nausea, seizures or eventually coma [8]. Despite the progressively increasing advances in diagnosis and treatment, the renal injury still represents an important risk factor for the development of serious complications as well as an independent mortality risk in hospitalized patients with sickle cell disease [9]. The lack of reliable diagnostic biomarkers for early structural kidney injuries results in an unacceptable delay in the clinical diagnosis, which strongly limits a prompt therapeutic approach [10].

Neutrophil Gelatinase-Associated Lipocalin (NGAL) also known as lipocalin-2 is a protein with a molecular weight of 25 $k D a$, it is synthesized and stored in the granules of neutrophils and emitted during various clinical cases [11,12]. It is used as a biomarker in the early diagnosis of renal damage in clinical practice [13]. Renal disorders (increase in urea and creatinine) have been reported as one of the prominent complications of sickle cell disease, which was attributed to both hemodynamic changes of chronic anemia and vaso-occlusive crises [14]. About $30 \%$ of adult sickle cell anemia subjects develop chronic kidney disease, which is a contributory factor in many sickle cell mortalities. NGAL has been reported to be associated with nephropathy in patients with Type 2 Diabetes and its presence in the blood or urine is an early indication of acute kidney injury $[15,16]$. Since NGAL serves as a promising biomarker for human acute kidney injury, this study, therefore investigated NGAL as a predictive marker for acute kidney injury among sickle cell subjects.

\section{Materials and Methods}

\section{Study design}

This is a case-control study conducted between January and July 2018. A total of fifty (50) sickle cell subjects (both males and females) aged between $18-40$ years attending the sickle cell clinic of Federal Medical Centre, Owo were randomly recruited for the study. A sickle cell in this study was defined as a disorder of the blood caused by inherited abnormal hemoglobin as described by William [8]. Twenty-five (25) healthy controls with " $A A^{\prime}$ " hemoglobin genotype from the family medicine outpatient clinic of the hospital were age, sex and socioeconomic status matched for the study.

\section{Consent and ethical approval}

Subjects participating in this study were fully briefed on the research protocols in the clinic after which they were required to sign a written consent. Ethical approval for the study was obtained from the Federal Medical Centre, Owo ethical review committee with registration number $\mathrm{FMC} / \mathrm{OW} / 380$ / VOL.LXIV/23.

\section{Inclusion criteria}

Homozygous sickle cell anemia (hemoglobin variant S) subjects, between 18 and 40 years of age and of both genders were recruited for the study. Control groups were apparently healthy individuals of both genders with the HbAA genotype between the ages of 18 to 40 years old. Same inclusion criteria were used for the control subjects but for the hemoglobin genotype AA and they had no symptoms of acute illness in the preceding month.

\section{Exclusion criteria}

Subjects with established complications such as Diabetes mellitus, hypertension, Human immunodeficiency virus (HIV), hepatitis and cancer; subjects outside the age range of 18 and 40 years, pregnant and breastfeeding mothers were all excluded from the study. The exclusion criteria for the controls were also the same as for subjects but for the hemoglobin genotype $A A$.

\section{Clinical data collection}

Study participants' information were collated using a short structured questionnaire detailing demographic characteristics, anthropometric data, drug history, family history of DM and or hypertension, the frequency of blood transfusion etc. Steadystate $\mathrm{Hb}$ SS subjects were those without crisis one-month preceding recruitment and weight was measured while the subjects were without shoes.

\section{Sampling technique and storage of sample}

Five milliliters ( $5 \mathrm{ml}$ ) of venous blood was aseptically obtained from the Median-cubital vein with $1 \mathrm{ml}$ dispensed into small size Ethylene Diamine Tetraacetic Acid (EDTA) bottle and $4 \mathrm{ml}$ into the plain bottle. The tubes were labeled and cooled in a box containing ice-packs while packed cell volume and hemoglobin electrophoresis were carried out on the EDTA specimens. Serum was separated from the plain tubes after retraction by centrifugation for 5 mins at $1792 \mathrm{~g}$, into plain bottles and stored at -200 degree celsius until the time of analysis.

\section{Analytical methods and procedures}

The Packed Cell Volume (PCV) was measured using the manual method and hemoglobin electrophoresis done using the electrophoretic machine. Levels of plasma Neutrophil Gelatinase-Associated Lipocalin (NGAL) were determined in the serum using ELISA kits obtained from Melsin Medical Comapany, USA. Plasma urea and creatinine levels were evaluated using the standard spectrophotometric technique.

\section{eGFR mathematical models calculation}

eGFR $(\mathrm{ml} / \mathrm{mins})=\{(140-$ age $($ year $)) \times$ weight $(\mathrm{kg})$ divided by $72\} \times$ serum creatinine. 
Multiply by 0.85 if female [17]

Where GFR=Glomerular Filtration Rate

\section{Statistical analysis}

Data analysis was done using Statistical Package for Social Scientist (SPSS) version 23.0. Analysis of variance (ANOVA) was used to test for the level of homogeneity at $p<0.05$ and Duncan's new multiple range tests to confirm where the significance occurred among the groups. The correlation was carried out to test the association between renal biochemical variables. A graphical plot of sensitivity (Receiver Operating Curve, ROC) was done and area under ROC (AUROC) of each marker (NGAL, Urea, and Creatinine) was compared using pair-wise comparison. $\mathrm{P}$ values less than 0.05 were considered significant.

\section{Results}

The mean weight and PCV were significantly $(p<0.05)$ lower in both steady sickle cell subjects and sickle cell patients with VOC when compared to the control group (Table 1). The plasma levels of NGAL and Urea were significantly $(p<0.05)$ increased in the Steady and VOC sickle cell subjects compared with the normal control. The GFR was however significantly $(p<0.05)$ reduced in both steady and VOC groups compared to the normal healthy control. The levels of urea and creatinine were increased significantly $(p<0.05)$ in the VOC SCD group compared with the steady SCD group. However, the circulating levels of NGAL were significantly $(p<0.05)$ reduced among the VOC SCD groups compared to the steady SCD group (Table 2). Table 3 shows a correlation between renal biomarkers (NGAL, urea, creatinine, and eGFR) in VOC subjects. There was a positive correlation between creatinine and urea in the VOC SCD groups (Table 3), while creatinine in the steady SCD group positively correlated with both urea and eGFR (Table 4). The diagnostic performance of NGAL, urea, and creatinine were assessed in the SCD groups. NGAL had an excellent higher area under the ROC curve (AUROC) of 0.939 than urea and creatinine. Urea also had a better AUROC of 0.861 than creatinine with area 0.663 (Figure 1).

Table 1: Age, weight and PCV profile of sickle cell subjects.

\begin{tabular}{|l|l|l|l|}
\hline & $\begin{array}{l}\text { Steady sickle cell } \\
\text { subjects }(\mathbf{n = 2 0})\end{array}$ & $\begin{array}{l}\text { Voc sickle cell } \\
\text { patients }(\mathbf{n = 3 0})\end{array}$ & Control (n=25) \\
\hline Age (years) & $24.15 \pm 6.49$ & $22.10 \pm 4.11$ & $22.24 \pm 5.11$ \\
\hline Weight (Kg) & $43.20 \pm 5.24^{\mathrm{a}}$ & $42.87 \pm 5.61^{\mathrm{a}}$ & $67.80 \pm 6.29^{\mathrm{b}, \mathrm{c}}$ \\
\hline PCV (\%) & $25.90 \pm 3.80^{\mathrm{a}, \mathrm{c}}$ & $22.32 \pm 5.18^{\mathrm{a}, \mathrm{b}}$ & $38.000^{*}$ \\
\hline
\end{tabular}

Note: Data presented as mean \pm standard deviation; " means significant at $p \leq 0.05$; $a=$ significantly different from control; $b=$ significantly different from steady sickle cell group; c=significantly different from VOC sickle cell group

Abbreviations: PCV=Packed Cell Volume, VOC=Vaso-Occlusive Crises, SCD=Sickle Cell Disease

Table 2: Biochemical parameters of sickle cell subjects.

\begin{tabular}{|c|c|c|c|c|}
\hline & $\begin{array}{l}\text { Steady sickle cell } \\
\text { subjects }(n=20)\end{array}$ & $\begin{array}{l}\text { VOC sickle cell patients } \\
(n=30)\end{array}$ & Control (n=25) & $p$-value \\
\hline GFR (ml/min) & $44.82 \pm 10.49^{a}$ & $48.48 \pm 7.81^{a}$ & $71.46 \pm 14.19^{b, c}$ & $0.000^{*}$ \\
\hline NGAL ( $\mu \mathrm{g} / \mathrm{dL})$ & $3.67 \pm 0.94^{\mathrm{a}, \mathrm{c}}$ & $3.15 \pm 1.02^{a, b}$ & $1.65 \pm 0.55^{b, c}$ & $0.000^{*}$ \\
\hline Urea (mg/dL) & $22.83 \pm 3.79^{a, c}$ & $25.45 \pm 4.79^{a, b}$ & $18.44 \pm 3.13^{b, c}$ & $0.000^{*}$ \\
\hline Creatinine (mg/dL) & $0.71 \pm 0.06^{c}$ & $0.76 \pm 0.05^{a, b}$ & $0.70 \pm 0.07^{c}$ & $0.001^{*}$ \\
\hline
\end{tabular}

Note: Data presented as mean \pm standard deviation; ${ }^{*}$ means significant at $p \leq 0.05$; ${ }^{\text {Significant }}$ at $P \leq 0.0$; $a=$ significantly different from control; $b=$ significantly different from Steady SCD group; c=significantly different from VOC SCD group

Abbreviations: GFR=Glomerular Filtration Rate, NGAL=Neutrophil Gelatinase-Associated Lipocalin, VOC=Vaso-Occlusive Crises, SCD=Sickle Cell Disease

Table 3: Correlation of renal biochemical indices of VOC sickle cell subjects.

\begin{tabular}{|l|l|l|l|l|}
\hline & & eGFR & NGAL & Urea \\
\hline \multirow{2}{*}{ eGFR } & $R$ & 1 & 0.244 & 0.182 \\
\cline { 2 - 5 } & P-value & & 0.194 & 0.337 \\
\hline \multirow{2}{*}{ NGAL } & $R$ & 0.244 & 1 & -0.113 \\
\cline { 2 - 5 } & P-value & 0.194 & 0.027 & 0.55 \\
\hline Urea & $R$ & 0.182 & -0.113 & 1 \\
\hline
\end{tabular}




\begin{tabular}{|l|l|l|l|l|l|}
\hline & P-value & 0.337 & 0.55 & & 0 \\
\hline \multirow{2}{*}{ Creatinine } & $\mathrm{R}$ & 0.216 & -0.027 & $0.967^{* *}$ & 1 \\
\cline { 2 - 6 } & P-value & 0.251 & 0.889 & 0 \\
\hline \multicolumn{2}{|l|}{ Note: Data presented as the correlation coefficient (r); ${ }^{* *}$ Correlation is significant at the 0.01 level (2-tailed) }
\end{tabular}

Table 4: Correlation of renal biochemical indices in steady sickle cell subjects.

\begin{tabular}{|l|l|l|l|l|l|}
\hline \multirow{2}{*}{ eGFR } & & eGFR & NGAL & Urea & Creatinine \\
\hline \multirow{2}{*}{ NGAL } & $\mathrm{R}$ & 1 & 0.195 & 0.253 & $0.465^{*}$ \\
\cline { 2 - 6 } & P-value & & 0.409 & 0.283 & 0.039 \\
\hline \multirow{2}{*}{ Urea } & $\mathrm{R}$ & 0.195 & 1 & 0.14 & 0.344 \\
\cline { 2 - 6 } & P-value & 0.409 & & 0.556 & 0.138 \\
\hline \multirow{2}{*}{ Creatinine } & $\mathrm{R}$ & 0.253 & 0.14 & $0.839^{* *}$ & 0 \\
\cline { 2 - 6 } & P-value & 0.283 & 0.556 & $0.839^{* *}$ & 1 \\
\hline \multirow{2}{*}{ Note: Data presented as correlation coefficient (r); ${ }^{*}$ Correlation is significant at the 0.05 level (2-tailed); ${ }^{* *}$ Correlation is significant at the 0.01 level (2-tailed) } \\
\cline { 2 - 6 }
\end{tabular}

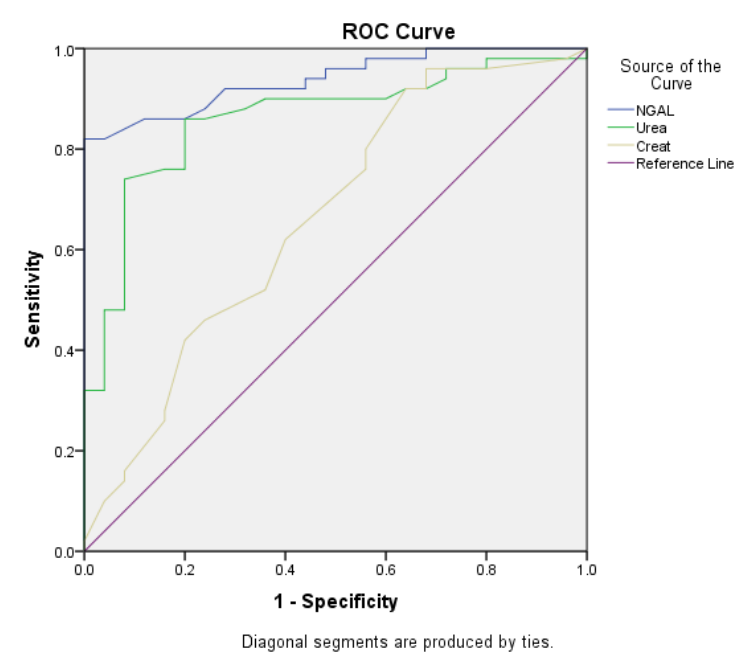

Figure 1: The Receiver Operating Curve (ROC) of serum levels of NGAL, Urea, and Creatinine in sickle cell subjects.

\section{Discussion}

Acute Kidney Injury (AKI) is characterized functionally by a rapid decline in the Glomerular Filtration Rate (GFR) and represents a common syndrome resulting from multiple causative factors with various clinical features such as blood urea, nitrogen, and creatinine caused by the accumulation of nitrogenous wastes [13]. Despite the progressively increasing advances in diagnosis and treatment of sickle cell disease, renal injury represents an important risk factor for the development of serious complications as well as an independent mortality risk in hospitalized sickle cell patients [9]. The lack of reliable biomarkers for the early structural kidney injuries results in an unacceptable delay in the clinical diagnosis, which strongly limits a prompt therapeutic approach $[10,18]$.

In this study, NGAL and urea were significantly increased while GFR was decreased in both Steady and VOC sickle cell subjects when compared to the control group respectively. The VOC SCD group showed higher circulating levels of urea and creatinine accompanied by reduced levels of NGAL than the steady SCD group, therefore, underpinning the significance of NGAL as a biomarker of early renal damage in sickle cell subjects since NGAL correlated positively with the duration of sickle cell disease mainly when GFR was decreased. NGAL is a known protein which regulates and binds the release of catalytic iron from insulted cells and is produced by the renals in response to acute injury $[19,20]$. Contrary to conventional markers, such as serum creatinine and blood urea nitrogen or serum; NGAL is not considered a marker of renal function, but a reflection of structural damage of renal cells. NGAL has previously been reported to be effective in the early diagnosis of Acute Kidney Injury (AKI) in several clinical settings [20-22] and also validated as a significant prognostic factor in cardiovascular morbidity [23]. This implies that NGAL may reflect a progression of the early renal structural damage occurring during the disease despite GFR remaining normal.

Serum NGAL had strong negative correlations with GFR in both vaso-occlusive and steady groups, indicating a significant association with renal function decline. Creatinine also showed a positive correlation with both urea and GFR in the steady SCD group, which may, therefore, be suggestive of an association of NGAL with the occurrence of Early Renal Disease (ERD). NGAL had an excellent and superior area under the ROC curve as compared to urea and creatinine when their diagnostic performances were evaluated using the "Area under the 
Receiver Operating Curve" (AUROC). This is consistent with the similar observations previously reported in patients with diabetes and hypertension $[15,20]$. The current study, to our knowledge; represents the first study assessing the predictive value of other early markers of renal injury, besides urea and creatinine, in two different groups of patients with sickle cell disease. This finding correlates with other studies on the predictive role of NGAL as an early clinically significant biomarker than Urine Albumin to Creatinine Ratio [UACR] [5].

\section{Conclusion}

In this cohort study, NGAL came across as a sensitive tool and an early biomarker for acute kidney injury in sickle cell subjects capable of mitigating the associated delayed diagnosis of AKI as its serum measurement apparently predicted the occurrence of AKI in the sickle cell patients. This finding is therefore clinically significant as NGAL measurement is widely available, cheap and sensitive in aiding early detection with a dynamic wide range for routine assessment in the management of SCD. Evidently, more work with larger multicenter studies are however still needed to corroborate these findings.

\section{Significance Statements}

This study identified NGAL as a novel marker for the prediction of AKI for routine assessment in the management of SCD and associated conditions, these findings may help researchers and clinicians diagnose structural kidney injuries early enough to initiate prompt therapeutic approaches. Despite NGAL being well established in this study as an early predictive marker for acute kidney injury among sickle cell subjects, the small sample size was a great limitation. Thus, a larger scale study would be integral to delineating the roles of NGAL as a reliable predictor of $A K I$ in sickle cell conditions.

\section{Competing and Conflicting Interests}

The authors declare no conflict of interests.

\section{Acknowledgment}

The authors appreciate the entire staff of Sickle Cell Clinic of Federal Medical Centre, Owo and all the participants for their supports during this study.

\section{References}

1. Webb S, Dobb G (2007) ARF, ATN or AKI? It's now acute kidney injury. Anaesth Intensive Care 35: 843-844.

2. Dan L, Anthony FS, Dennis KL, Stephen $\mathrm{HL}$, Jameson JL, et al. (2011) Harrison's Principles of Internal Medicine. (18th Edn), McGraw-Hill Education, Europe pp: 186-187.

3. Okpala IE (2004) Assessment of severity and hydroxyurea therapy in sickle cell disease. Practical Management of Haemoglobinopathies. (1st Edn ), Wiley-Blackwell.

4. Emokpae MA, Uadia PO, Gadzama AA (2010) Correlation of oxidative stress and inflammatory markers with the severity of sickle cell nephropathy. Ann Afr Med 9: 3.
5. Akinlade KS, Atere AD, Olaniyi JA, Rahamon SK, Adewale CO (2013) Serum copeptin and cortisol do not accurately predict sickle cell anaemia vaso-occlusive crisis as C-reactive protein. PLoS One 8: e77913.

6. Ware RE, Rees RC, Sarnaik SA, lyer RV, Alvarez OA, et al. (2010) Renal function in infants with sickle cell anemia: baseline data from the BABY HUG trial. J Pediatr 156: 66-70.

7. Powars DR, Elliott-Mills DD, Chan L, Niland J, Hiti AL, et al. (1991) Chronic renal failure in sickle cell disease: risk factors, clinical course, and mortality. Ann Intern Med 115: 614-620.

8. William CS (2016) Sickle cell disease: A review of nonpharmacological approaches for pain. J Pain Symptom Manage 51: 163-177.

9. Clerico A, Galli C, Fortunato A, Ronco C (2012) Neutrophil Gelatinase-associated Lipocalin (NGAL) as biomarker of acute kidney injury: A review of the laboratory characteristics and clinical evidences. Clinical Chemistry and Laboratory Medicine (CCLM) 50: 1505-1517.

10. Clerico A, Galli C, Fortunato A, Ronco C (2012) Neutrophil gelatinase-associated lipocalin (NGAL) as biomarker of acute kidney injury: A review of the laboratory characteristics and clinical evidences. Clinical Chemistry and Laboratory Medicine (CCLM) 50: 1505-1517.

11. Kjeldsen L, Cowland JB, Borregaard N (2000) Human neutrophil gelatinase-associated lipocalin and homologous proteins in rat and mouse. Biochim Biophys Acta-Protein Structure and Molecular Enzymology 1482: 272-283.

12. Krawczeski CD, Woo JG, Wang Y, Bennett MR, Ma Q, et al. (2011) Neutrophil gelatinase-associated lipocalin concentrations predict development of acute kidney injury in neonates and children after cardiopulmonary bypass. J Pediatr 158: 1009-1015.

13. Devarajan P (2010) Neutrophil gelatinase-associated lipocalin: A promising biomarker for human acute kidney injury. Biomark Med 4: $265-280$.

14. Bolarinwa RA, Akinlade KS, Kuti MAO, Olawale OO, Akinola NO (2012) Renal disease in adult Nigerians with sickle cell anemia: a report of prevalence, clinical features and risk factors. Saudi J Kidney Dis Transpl 23: 171.

15. Baumert M, Surmiak P, Więcek A, Walencka Z (2017) Serum NGAL and copeptin levels as predictors of acute kidney injury in asphyxiated neonates. Clin Exp Nephrol 21: 658-664.

16. Wu J, Shao X, Lu K, Zhou J, Ren M, et al. (2017) Urinary RBP and NGAL Levels are associated with nephropathy in patients with type 2 diabetes. Cell Physiol Biochem 42: 594-602.

17. Asnani MR, Reid ME (2013) Determining glomerular filtration rate in homozygous sickle cell disease: utility of serum creatinine based estimating equations. PloS One 8: e69922.

18. Yusuf R, Hassan A, Ibrahim I, Babadoko A, Ibinaiye P (2017) Assessment of kidney function in sickle cell anemia patients in Zaria, Nigeria. Sahel JA 20: 21.

19. McCullough PA, Williams FJ, Stivers DN, Cannon L, Dixon S, et al. (2012) Neutrophil gelatinase-associated lipocalin: a novel marker of contrast nephropathy risk. Am J Nephrol 35: 509-514.

20. Ezenwaka CE, Idris S, Davis G, Roberts L (2016) Measurement of neutrophil gelatinase-associated lipocalin (NGAL) in patients with non-communicable diseases: any additional benefit? Arch Physiol Biochem 122: 70-74. 
21. Haase $M$, Bellomo R, Devarajan $P$, Schlattmann $P$, Haase-Fielitz $A$, et al. (2009) Accuracy of Neutrophil Gelatinase-associated Lipocalin (NGAL) in diagnosis and prognosis in acute kidney injury: A systematic review and meta-analysis. Am J Kidney Dis 54: 1012-1024.

22. Clerico A, Galli C, Fortunato A, Ronco C (2012) Neutrophil Gelatinase-associated Lipocalin (NGAL) as biomarker of acute kidney injury: a review of the laboratory characteristics and clinical evidences. Clinical Chemistry and Laboratory Medicine (CCLM) 50: 1505-1517.

23. Hawkins R (2011) New biomarkers of acute kidney injury and the cardio-renal syndrome. Korean J Lab Med 31: 72-80. 